\title{
Desenvolvimento de Aplicativo para Ensino de Língua
}

\section{Portuguesa}

\author{
Heloneida Camila Costa Coelho ${ }^{1}$, Olavo Nylander Brito Neto ${ }^{1}$
}

\author{
${ }^{1}$ Instituto Federal de Educação,Ciência e Tecnologia do Amapá (IFAP) - 68.090-398 - \\ Macapá, AP - Brasil \\ (heloneidacamila@gmail.com, Olavo.britodifap.edu.br)
}

\begin{abstract}
Resumo: Os aplicativos educacionais podem estimular o interesse do aluno e contribuir no método de ensino aprendizagem. Sabe-se que os alunos utilizam muito os equipamentos portáteis, e que estes podem ser utilizados às boas práticas pedagógicas. Este artigo apresenta o desenvolvimento de um aplicativo educacional para o ensino da Língua Portuguesa, baseado na ferramenta Android, como forma de incentivar o uso de tecnologia na educação. A metodologia adotada envolveu um breve estudo bibliográfico acerca do tema e o desenvolvimento de um protótipo de aplicativo para dispositivo móvel. O estudo se mostra plausível, por demonstrar que os aplicativos são relevantes, e podem contribuir com o sistema educacional.
\end{abstract}

\begin{abstract}
Educational applications can stimulate student interest and contribute to the teaching-learning method. It is known that students use portable equipment a lot, and that they can be used to good pedagogical practices. This article presents the development of an educational application for Portuguese language teaching, based on the Android tool, as a way to encourage the use of technology in education. The adopted methodology involved a brief bibliographical study about the theme and the development of a mobile app prototype. The study is plausible because it shows that applications are relevant and can contribute to the education system.
\end{abstract}

\section{Cenário de Uso}

O protótipo do jogo educacional Brincando com Palavras desenvolvido na disciplina de aplicativos para dispositivo móveis tem como objetivo apresentar uma proposta educacional de acesso livre, aliada ao uso de tecnologia, neste caso, desenvolvida como apoio pedagógico para o ensino da Língua Portuguesa no Ensino Fundamental. Serão apresentadas as ferramentas e linguagens de programação utilizadas em sua construção e ainda as possibilidades oferecidas pelo aplicativo para a aprendizagem móvel.

Em sua análise sobre a educação Tavares (2002) levanta questões sobre o perfil do estudante do futuro, a mudança que ocorre na organização escolar para atender a estes estudantes, os métodos de ensino que serão utilizados, o papel do professor, às novas necessidades em termos de equipamentos e tecnologias. Todos esses recursos precisam estar disponíveis para que o sujeito absorva novos conhecimentos em qualquer momento e lugar. 
VIII Congresso Brasileiro de Informática na Educação (CBIE 2019)

Anais do XXV Workshop de Informática na Escola (WIE 2019)

Para Pazzini e Campos (2018) atualmente existe uma relação entre cultura digital e educação inovadora, onde temos uma reflexão sobre os usos e opções de tecnologias midiáticas para serem trabalhadas na educação, sendo assim, os profissionais que devem se atualizar e verificar a melhor maneira de aliar a tecnologia ao ensino. A proposta deste protótipo de aplicativo é incentivar os alunos quanto a importância da escrita correta, como meio de ampliar seu conhecimento, além de facilitar sua comunicação e formar a base para o próprio processo de aprendizagem, através de uma competição entre ele mesmo e o software.

Sabe-se que o ensino da língua Portuguesa é uma tarefa árdua para os docentes, os conteúdos são extensos com uma carga horária elevada para poder cumpri-los, sendo assim, eles buscam constantemente alternativas viáveis para trabalhar os diversos conteúdos de maneira mais atrativa a os alunos. A escolha desse tema está relacionada aos interesses educacionais, e também como forma de disseminar o conhecimento acerca de recursos disponíveis dentro do contexto tecnológico. Sabe-se que as atuais dúvidas sobre como tratar a ortografia são o reflexo dos avanços que temos vivido, na área de língua portuguesa, e que nos leva a priorizar, a formação de alunos que possam ler e produzir textos corretamente.

No dia a dia, os erros de ortografia funcionam como forma de censura e de discriminação entre os colegas, dentro e fora da escola, muitos discentes não gostam de expor sua escrita por "medo" de possíveis erros. No interior da escola, a questão tornase extremamente grave, pois as peculiaridades da Língua Portuguesa confundem muito os alunos por toda sua vida estudantil. Infelizmente ensinar a ortografia é complexo por se tratar de conteúdos cheio de regras. Para MORAIS (1998), a ortografia é uma convenção social, cuja finalidade é ajudar a comunicação escrita, cabe a nós compreendermos as peculiaridades de aprendizagem e assimilação de cada pessoa.

\section{Desenvolvimento}

O desenvolvimento do Brincando com Palavras iniciou após um breve estudo bibliográfico, para embasar as informações básicas do aplicativo educacional. Devido ao rápido processo de evolução tecnológica dos últimos anos, se tornou imprescindível aliar a tecnologia a educação tentando manter um equilíbrio entre as duas, sabe-se que esse processo exige do professor, uma nova maneira de agir e pensar na educação. É importante que os profissionais reflitam sobre a influência constante e crescente que a informática tem em nossas vidas.

Após as buscas a avaliação de alguns temas, foi realizado um Brainstorming em sala de aula, que de acordo com KAMINSK (2012) é uma técnica que surgiu na década de 30 com o publicitário Alex Osborn, e tem como objetivo realizar troca de ideias entre os participantes, incentivando uns aos outros a modificar, combinar ou melhorar o que foi apresentado com base nas sugestões de outros colegas do grupo, todos estão livres para expor as idéias para contribuir com o tema de estudo. Optou-se então por utilizar um jogo para Língua Portuguesa voltado a questões ortográficas, utilizando a colaboração dos colegas no Brainstorming.

Para dar encaminhamento na produção do Brincando com Palavras foi necessário fazer um levantamento de requisitos básicos para seu funcionamento: Quantidade de telas do aplicativo; cores e imagens, além dos botões de cada tela; os áudios que serão utilizados; e o desenvolvimento do layout geral do aplicativo. Como 
VIII Congresso Brasileiro de Informática na Educação (CBIE 2019)

Anais do XXV Workshop de Informática na Escola (WIE 2019)

descritos, os requisitos elencados foram as propriedades básicas para iniciar o projeto e são considerados indispensáveis para que o aplicativo funcione correto e seja satisfatório para utilização do docente em sala de aula.

Após definir os requisitos básicos do Brincando com Palavras, montou-se então um Wireframe, neste caso, com as sugestões de possíveis telas do aplicativo. Com base no conceito de Van Dijck (2003), que diz que os wireframes são esboços da interface que o usuário terá contato, indicando como funcionarão links, botões funcionais e outros elementos que possam influenciar o uso da interface e a relação entre eles. Sendo assim, nesta fase foi definido o layout de cada botão e alinhamento das telas, já verificando a simetria dos ícones, dimensões e a qualidade de navegabilidade por meio do usuário.

Para desenvolver este aplicativo, foi utilizado a plataforma virtual App Inventor, que se mostrou viável, por ser uma ferramenta fácil de manusear, e por ser uma plataforma gratuita, de código aberto, disponível via web, facilitando o acesso. Ele permite que programadores leigos desenvolvam aplicativos para o sistema operacional Android, de forma simples e rápida, pois trabalha com programação em blocos, transformando assim o desenvolvimento do aplicativo mais prático e rápido.

Reconhecendo esse potencial em massa dos dispositivos móveis, e associando isto à prática do ensino, surgem diariamente diversos aplicativos educacionais. Sendo assim, para desenvolver o Brincando com Palavras foi necessário investigar a existência de outros aplicativos semelhantes, encontramos então o jogo Soletrando, o Jogos Educativos: Soletrar, e o Silabando, esses jogos tem características similares ao Brincando com Palavras, porém são diferentes em layout e modo de jogo, vale ressaltar que eles são gratuitos e podem ser baixados em lojas virtuais para aplicativos móveis.

\section{Apresentação do Software}

O aplicativo "Brincando com palavras" tem a intenção de explorar a competência lingüística dos alunos, para que busquem sempre o aprimoramento de suas habilidades de leitura, escrita, interpretação, além de aplicar o que aprendem, tanto quando lêem como quando escrevem. Saber escrever é diferente de saber com qual letra se escreve a referida palavra. Este protótipo então visa estimula o aluno à observação da grafia correta e induz a investigação, pois quando surge a dúvida na escrita, o aluno pode recorrer ao dicionário, por exemplo, e assim cria o hábito de pesquisa quando a situação lhe for propicia.

A proposta do aplicativo é ser utilizada prioritariamente com alunos de ensino fundamental, por isso, pensou-se em telas de fácil manuseio, layout simples, mas que fosse atrativa para utilização de qualquer pessoa. Este protótipo foi desenvolvido com 30 palavras, mas a ideia é atualizar o vocabulário frequentemente. O jogo se divide três telas principais, sendo que na primeira, o usuário tem disponível três botões, o botão de "TUTORIAL", onde ele é encaminhado para outra tela que explica a funcionalidade do jogo, nesta tela o usuário pode usar o botão "VOLTAR", para retornar à tela inicial, ou o botão "INICIAR JOGO" que o encaminha para o jogo. Ainda na tela inicial temos também o botão "EXIT" que fecha aplicação, ou o usuário pode usar o botão "PLAY", que irá passar para tela de início de jogo. 

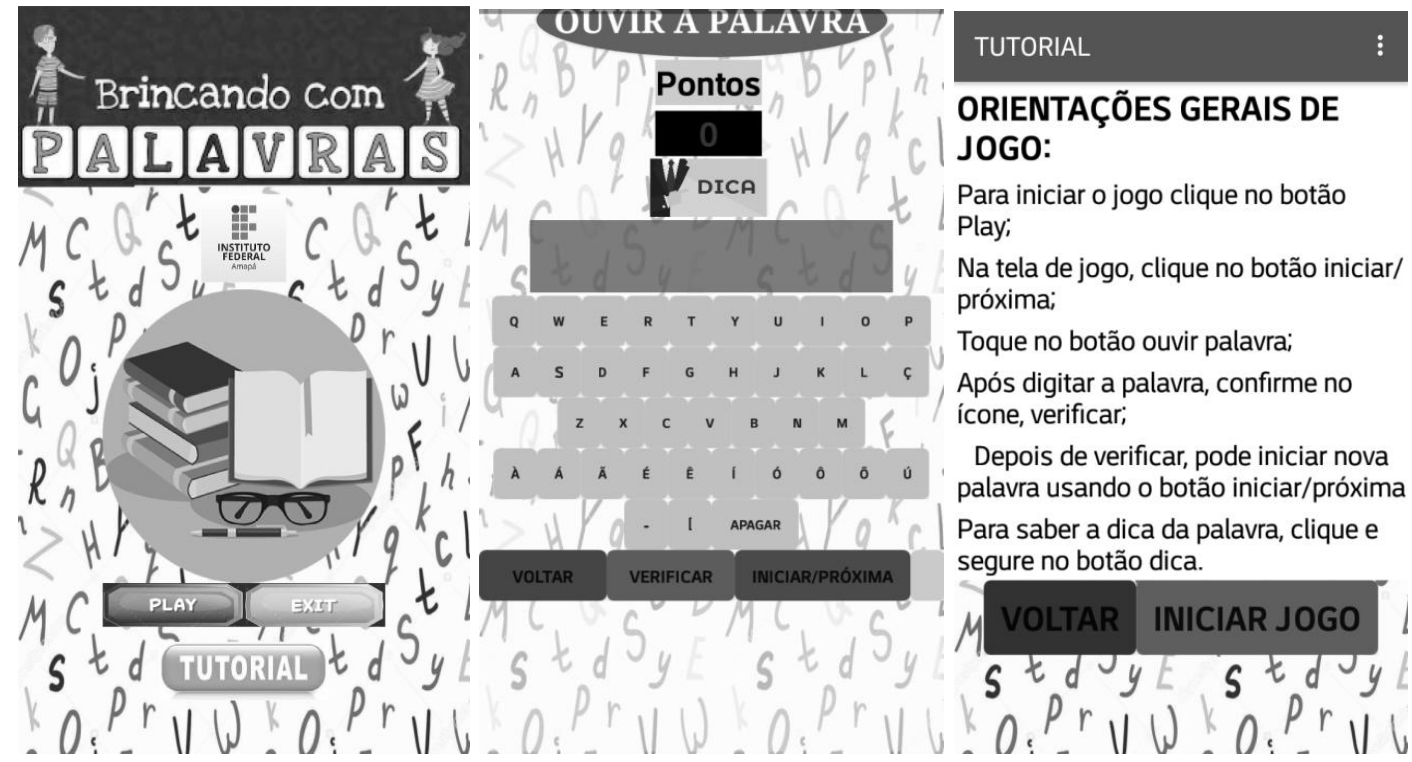

Figura 1 - Telas do aplicativo Brincando com Palavras.

Na segunda tela, onde o jogo inicia, temos 3 botões de controle de atividades, que são o de "VOLTAR", "VERIFICAR" E "INICIAR/PRÓXIMA". Outro item nesta tela que é importante é o botão "ouvir palavra", nele o aplicativo apresenta o áudio de cada palavra, e este arquivo deve está em boa qualidade de som e dicção para o entendimento do usuário. $\mathrm{O}$ aplicativo possui botões referentes a cada letra do teclado, optou-se por esta configuração para evitar o uso do corretor ortográfico, que faz parte da configuração de teclado normal.

Os primeiros testes desse protótipo foram realizados com 30 alunos de turmas de $5^{\circ}$ ano do ensino fundamental, onde eles definiram alguns pontos positivos, como o layout e a dinâmica do aplicativo, já como negativos, eles indicaram a quantidade de palavras que poderia ser maior, além de solicitar mais opções de pontuação.

\section{Considerações}

Os aspectos abordados durante a contextualização deste artigo estão baseados em pesquisas que apontam a importância de aliar tecnologia a práticas de ensino. Apesar de ainda ser um protótipo, percebe-se que o aplicativo tem potencial para ser utilizado em sala, pois esta ferramenta aliou bem, o uso da tecnologia e o ensino, este que é alvo de reclamações constante de alunos, por acharem o ensino monótono, e por falta de interesse dos próprios discentes.

É evidente que o aplicativo desenvolvido nesse estudo ainda precisa ser aprimorado, mesmo assim, ele já se mostrou uma boa ferramenta no uso escolar, visando avaliar diretamente a habilidade ortográfica dos alunos, item este, que é fundamental para o desenvolvimento da escrita individual.

Ao completar esta fase do estudo pode-se afirmar que este aplicativo vem trazer novas perspectivas de ensino, ajudando o aluno a aprender de forma lúdica e atrativa a Língua Portuguesa. Esta pesquisa analisou de fato, um problema presente na educação, e considera-se que o Brincando com Palavras pode ser uma importante ferramenta didática que busca eficiência no processo de ensino aprendizagem dos alunos, desenvolvendo assim uma boa relação entre a prática docente e o uso de tecnologias no 
VIII Congresso Brasileiro de Informática na Educação (CBIE 2019)

Anais do XXV Workshop de Informática na Escola (WIE 2019)

ensino. É notório que o celular pode ser um aliado da educação, já que ganhou grande espaço no ambiente escolar, cabe aos profissionais da educação se conectarem a essas novas tendências e buscar conhecer as opções que eles podem utilizar, para aprimorar a qualidade do ensino.

\section{Referências}

Morais, Arthur Gomes. (1998) Ortografia: ensinar e aprender. São Paulo; Ática,.

Van Dijck, J. (2006) Picturizing science: The science documentary as multimedia spectacle. International Journal of Cultural Studies, vol. 9, n. 5.

Tavares, Neide Rodriguez Barea. (2002) História da informática educacional no Brasil observada a partir de três projetos públicos. São Paulo: Escola do Futuro. Disponível em: <http://www.lapeq.fe.usp.br/textos/te/tepdf/neide.pdf>. Acesso em 15 de Maio de 2019.

Kaminski, Paulo Carlos, (2012) Desenvolvendo produtos planejamento, criatividade e qualidade. Rio de Janeiro LTC.

Passini, L. H. S. and Campos, G. H. B. (2004). A rota da aprendizagem: seriam os games uma via?. In VII Congresso Brasileiro de Informática na Educação (CBIE 2018), Anais do XXIX Simpósio Brasileiro de Informática na Educação (SBIE 2018). Disponível em: 〈http://dx.doi.org/10.5753/cbie.sbie.2018.1771〉. Acesso em 18 de Setembro de 2019. 